Gravity and Melancholia - Journey's End or A New Beginning?

I must always point to an analogy according to which one had been thinking, but which one did not recognise as an analogy.

Ludwig Wittgenstein Big Typescript Section 87 pp. 409

Our spatial concept UP arises out of our spatial experience. We have bodies and we stand erect. Almost every movement we make involves a motor program that either changes our up-down orientation, maintains it, presupposes it, or takes it into account in some way. [...] Thus UP is not understood purely in its own terms but emerges from the collection of constantly performed motor functions having to do with our erect position relative to the gravitational field we live in. Imagine a spherical being living outside any gravitational field, with no knowledge or imagination of any other kind of experience. What could UP possibly mean to such a being? The answer to this question would depend, not only on the physiology of this spherical being, but also on its culture.

Lakoff and Johnson 2003 (1980) Metaphors We Live By pp. 56

In a scene from Lars von Trier's Melancholia, which will likely be difficult to watch for anyone who has been afflicted by depression, Kirsten Dunst's character, Justine, is being helped and encouraged by her sister Claire to climb into a bath. Justine's melancholia, her depression, seems to afflict her in a manner that makes it appear as if the force of gravity had for her increased. For as certain ailments, such as shingles, can seem to magnify the force of a touch to the skin, making the slightest touch of the skin painful through a hyper-sensitivity of the nerves, then depression can seem to the afflicted to magnify resistances to movement, such as gravitational force, through its erosion of the power of the will. Gravity seems to weigh on Justine so heavily that she can barely lift her leg, so as to step into the bath. The world that for those around her offers little resistance and constraint, for Justine suffocates her emotionally and physically, resulting in an inertia that makes it appear, in this scene, that for her to move is akin to wading through bitumen.

This is the same person we saw in the opening scene of part one of the film, on her wedding day, almost literally stuck in a rut, unable to turn the corner. The baggage that came with marriagesymbolised in this scene by the elongated wedding limousine and impractical white heavily-ruched dress, complete with long train-made continuing her journey more difficult. For Justine, therefore, right at the outset of von Trier's film, adherence to social conventions serve to slow her down, weigh her down, and make life's journey seem impossible to complete. As the film progresses, Justine becomes exhausted by having to carry this baggage. She first tries to shed it, beginning on her 
wedding night, but ultimately collapses under its weight, as we see in those scenes at the start of part two of the film, such as the bath scene with which I began.

In contrast to the scene in Melancholia, which I opened by drawing attention to, Alfonso Cuaron's film Gravity is, to the exclusion of one final scene, focussed upon Sandra Bullock's character, Dr Ryan Stone, floating free in gravity-free outer space, trying to make it back to earth and find her feet. Ryan Stone is not suffering under the weight of life's accumulated baggage, but struggling to get to grips with life, to find her feet, to know which way is up and which down. As if to emphasise the point, it pays to be reminded of a piece of early dialogue at the opening of the film. We have learned that Dr Stone is on her first NASA mission and that she is suffering from nausea, which is induced by the disorienting effects of being in space: gravity free and free of fixed up/down reference points. We then witness disaster strike as space debris hits the shuttle on which Stone and the other astronauts are working. In the immediate aftermath of the disaster, Dr Stone spins off, attached to a piece of the shuttle that has sheared off. As Stone spins further away from the shuttle, we hear her commander and veteran astronaut Matt Kowalski (George Clooney) shout via the intercom: "Detach! You need to detach. The arm is going to carry you too far. You need to Detach!"

So, if I continue by remarking that the films I have opened by discussing, von Trier's Melancholia (2011) and Cuaron's Gravity (2013), are allegorical that will very likely serve as information to no one. Let's think a little more about Gravity. From the title, to key scenes, there are signposts a-plenty for those who might otherwise have missed the allegorical nature of the film: its point. Similarly, von Trier's Melancholia is pretty obviously allegorical, the signposting begins with the film's title and name of the planet, which is on a collision course with Earth. But what is the conceptual metaphor, on which these films draw and explore? Neither director was striving for literary subtlety in the conventional sense, their films are literary in a different way: like Orwell's Animal Farm, or Carroll's Alice in Wonderland, their allegorical status is up front.

Where much literary work proceeds by telling a story about the characters therein, which contains within it allusion to generic themes, overtly allegorical work begins with the generic themes and then proceeds to shed light on these through exploration, through applying pressure to, and testing the limits of, the metaphors that might be employed in depiction of those themes. A television programme like The Wire might well be about capitalism and The War on Terror, but a 
large part of its power, and the acclaim it has gained as a piece of art, is found in the masterful way in which these themes seem to naturally or organically emerge out of the telling of believable stories about richly depicted, authentic characters, and about the character dynamics which exist within the structural constraints of the Baltimore socio-economic and cultural context. The Wire is a brilliant piece of dramatised literature in my view, because of the extent to which the characters are treated with honesty and integrity, and not forged solely, or even predominantly, for the purpose of pursuing the generic goals and themes. This can seem to make the generic themes that emerge from the series all the more powerful in some respects. It might also be why many fans and critics were disappointed with the final, fifth, season. Here the desire to conclude seemed to detract from the character-led exploration of themes in the first four seasons.

But this is not the only way one might operate. One might choose to straightforwardly address the generic themes. How might you do this? Generic themes are, by their nature, also abstract and in being so are often understood in terms of the metaphors we employ in talking about them. Put another way, abstract thought is often given content by the metaphorical employment of concepts drawn from non-abstract, concrete, domains. For example, if you want to better understand a life lived in the shadow of depression, one way is to listen to testimonies of and stories about specific individuals who live with depression. An alternative approach might be to interrogate the modes of expression which are widely employed, and the metaphors we draw upon to describe the way depression relates to our lives. We might then see how these metaphors illustrate and/or restrict our understanding and even, potentially feed-into, or shape, the content of the experience.

\section{Cognitive Frames}

The philosophy of Ludwig Wittgenstein and work over the past three or so decades in cognitive linguistics share an interest in the extent to which analogies (Wittgenstein) and conceptual metaphors (CL), what were once called dead metaphors, serve to frame how we take-in the world, or operate as the background against which judgement, dialogue, agreement and disagreement take place. One way of illustrating this point is by a question: when there is disagreement over an issue, to what extent is that disagreement taking place within a framework of shared assumptions and to what extent is it not actually a disagreement but a confusion which emerges from a clash of frames or lack of shared assumptions? Philosophical problems are typically not disagreements but framework confusions or clashes. One might suggest this as a strong candidate for a working 
definition of philosophy, at least the approach that Wittgenstein advocated in the The Philosophical Investigations. The programme of cognitive linguistics pioneered by Lakoff and Johnson, and explicitly indebted to Wittgenstein (and Merleau-Ponty) has taken this on and has sought to identify the structure: concepts from a source domain employed metaphorically in a target domains, serve to frame discussions, disagreement and judgement.

For Wittgenstein, philosophical problems, if they are genuinely philosophical rather than being mathematical, empirical, etc., are borne of an unacknowledged commitment to a certain way of framing an issue: certain pictures of the way things must be lying in the unconscious and constraining thought. The appropriate way of dealing with philosophical problems, therefore, is not to theorise a solution to the problem, because this would leave both in-place and unquestioned the potentially misleading or constraining frame, but rather to unpack, or uncover, the source of the problem in the background or underlying assumptions: in the unacknowledged analogies. The parallels with the more recent programme of cognitive linguistics are both strong and telling.

The programme of cognitive linguistics has sought to demonstrate the extent to which our way of thinking about the world is framed by conceptual metaphor. The idea is that much of our thought, particularly abstract thought, is structured by metaphors which have their origins in concepts drawn from other, source, domains. So, for example, in thinking and talking about an individual's life or human life in general (the target domain) we do so by drawing on metaphors of travel or journeying, which we might bring together under the heading of "life is a journey". The conceptual metaphor of "life is a journey", draws on concepts used when we talk, literally, of travelling from one location to another, having to carry heavy baggage in doing so, accumulating baggage as the journey continues, taking wrong turns, coming up against dead-ends, and struggling up hills. One could continue...

Metaphors, like all analogies, can at turns both enable and constrain, illustrate and mislead, shed light and elicit dark spots. While invoking the concept of a journey, and derivative concepts such as, dead-end, by-pass, detour, terminus, up-hill, cul-de-sac, down-hill, carrying baggage and so on, can be enabling and might bring sense to reflections on one's life or life in general, it might also impose constraints. Because lives are not journeys, life is not subject to the same material constraints as a journey, and the analogy will, therefore, inevitably breakdown sooner or later. While the "life is a Journey" metaphor has been so thoroughly absorbed into our language, it is not the only conceptual metaphor employed here. We might also note the "tree of life" metaphor, where life can be talked about as something which grows and, by extension, can be cultivated. 
Indeed, one might like to explore the extent to which the "life as a journey" metaphor is particularly well-suited to modern conceptions of life (life lived in Modernity), where each embarks on their own journey, being (in theory) free to select their destination, and, within certain constraints, the route they take. Life as a road movie, or river journey film. (What works for you? Apocalypse Now, Aguirre: Wrath of God or The African Queen?). In contrast, the "tree of life" analogy, with its derivative concepts of cultivation, the requirement for fertile soil and a supportive environment in which to grow and flourish, seems to be at home in a pre-modern way of viewing life that fell out of fashion in the West during the Enlightenment. Some readers will be ahead of me here, the word flourishing will have likely served as a trigger-word so as to indicate the extent to which the "tree of life" metaphor maps on to a virtue ethic framework, where moral philosophy is about tutelage in the excellences of character required to enable a person to live a good life, to flourish.

While therefore not exclusive, the "life is a journey" metaphor is so well established in secularmodern contexts as to be a wholly natural way of talking about life. Other metaphors, employed in other domains, might be seen as less natural, contestable and even morally or politically problematic.

When a conceptual metaphor is so thoroughly absorbed into our way of talking about a specific domain that it seems wholly natural and rarely serves to trigger thoughts about its status as a metaphor, then it can serve to smuggle-in, import, certain thought-constraining assumptions about the target domain. We might say that what we thought to be dead metaphors are actually zombie metaphors. The constraints that these zombie metaphors impose hold only because of the role of the metaphor and not because of the nature of the domain. It is in this way that we might overlook what is there before our eyes: the constraints imposed on our conception of the target domain (our life) by the metaphor drawn from the source domain (journeying). Think, for example, of the employment of the metaphor of cleanliness in the context of infectious disease. People will often remark, on receiving a negative test result, that they are clean (in the same way a recovering drug addict might), in doing so they open the door to a moral or evaluative tainting of the infection status by implying that to have a positive test, to be infected, is to be dirty. Here what might be assumed to be a dead metaphor serves to introduce a moral or evaluative dimension and by extension maybe even a source of shame and stigma where there otherwise might be no such dimension. 
The existence of cognitive frames, the role played by conceptual metaphor, therefore provides motivation enough for allegorical literature. Taking the metaphor of "life is a journey" and exploring it in inventive ways might well give us new perspectives, bring to light new aspects on, our lives. This is, I believe, what takes place in Cuaron's Gravity and von Trier's Melancholia. Both films explore and subject to interrogation one of the most pervasive ways in which our ways of discussing, judging and disagreeing about our lives are framed.

Gravity and Melancholia as philosophy

So, one might see Cuaron's Gravity as a CGI riff on the metaphor of 'life is a journey'. This is undertaken through the tracking of Ryan Stone's journey back to Earth, following the catastrophe the took out the shuttle and ultimately ended the lives of her fellow astronauts. Ryan Stone is on her first mission, she is a bereaved mother who we learn has never come to terms with the loss. Her journey back to life is a rebirth, something which is flagged in various ways: most notably in the scene as she first enters the International Space Station, Soyuz: the camera pulls back, and Stone, having shed her space suit, curls-up almost naked in the foetal position, in the gravity-free environment, (sub-)framed by the circular door. Finally, as she reaches earth, she again has to shed her suit, and swim to the surface for breath. As she reaches the shore of the lake, she unsteadily climbs to her feet, and takes tentative, unsure steps-toddler-like. Her journey, her impossible journey, has led to her rebirth. Those final, tentative and unsteady steps at the close of the film have, I suggest, a hermeneutic significance. Ryan Stone's journey, which appeared hopeless and therefore pointless, following the accident (both), became achievable, through treating it as a series of stages: steps. Each step was difficult, but achievable. As she stands on the lake shore, the camera shoots her from the ground. Now she, and we, know which way is up.

At the film's beginning we encountered Ryan Stone nauseous, and, soon after, spinning in a frictionless void, with no anchor points. By the time we leave her at the film's close, she has her feet on the ground. When all seemed lost, nauseous and spinning out of control, it was like her purpose, the point of life, was so far ahead as to be out of view, leaving her cut adrift and purposeless. As she regains focus (something Matt Kowalski repeatedly implores her to do) she does so by focussing on things within her field of vision, and not trying and failing to focus on things beyond that field of vision. This gives point to her continuing her journey, for if you want to make a journey you need to have a point, you need a destination. As Ryan Stone remarks to Matt Kowalski, since she heard of 
her daughter's death while driving, she has since taken to getting in the car and just (pointlessly) driving.

The film invites us to explore the metaphor of 'life is a journey', it points us in the direction of an analogy according to which we had been thinking but which we, perhaps, did not recognise as an analogy (cf. Wittgenstein BT). In doing so, the film facilitates for the viewer, as the Wittgensteinian philosopher might for their interlocutor, or the psychotherapist might for their client, the bringing to consciousness of the analogy, its capacity to constrain our thinking about our life and perhaps even, considered under a different aspect, its capacity to enable us in our pursuit of a meaningful life. While the 'life is a journey' metaphor is not rejected by Cuaron's film, our particular unacknowledged conception of the metaphor that had hitherto framed and guided our thinking might well be brought to consciousness, disturbed and disrupted. We might have gained some clarity about the role of the analogy in our thinking about our life. In being so the frames through which we reflect on life might change. This is Gravity as philosophy.

Von Trier's Melancholia is a little less constrained in its execution of its goal and it is also a little less overtly focussed upon the Life is a Journey metaphor. However, it is, I suggest, still to be considered in large part as pointing us in the direction of the journey analogy and how that analogy is operative through the modes of expression that are entailed by the metaphor of life is a journey.

So, for example, modes of expression that invoke metaphors of constraint are expressive of the master metaphor of 'life is a journey': the journey is difficult because of the constraints. So, from the film's first scenes, where we see characters from the film sinking into the hitherto-firm ground as they traverse the landscape, accompanied by music from Wagner's Tristan und Isolde (an opera inspired by the philosophy of Schopenhauer ...), to the scenes already discussed at the opening of this short essay, above, we can see that reflections on life and depression are framed by the life is a journey metaphor. Put in Wittgenstein's terms: that is the analogy according to which we have been thinking and to which Melancholia wants to direct our attention.

We might then add to this the passage of dialogue that takes place between the sisters, Justine and Claire, 28 minutes into the film, half way through Justine's wedding. Justine has retreated to the bedroom and lies motionless in bed, still in her bridal gown. Claire comes to encourage her to return to her wedding reception:

Justine: "I have to pull myself together" (said in a very flat tone of voice)

Claire: "What's going on Justine?" 
Justine: "I'm trudging through this grey woolly yarn ... its clinging to my legs, it's really heavy to drag along."

Perhaps we might propose that Melancholia is in part a reflection on a specific kind of pathology of the will (and certainly not only of Justine's) and in being so, it inevitably, focusses our attention on the analogies that frame our expressions of will. It does so through the metaphors which permeate the dialogue, but also visually, by putting the metaphors before us on screen.

Neither film sets out to provide you with an answer. Both work as philosophy as therapy. Just as the therapy session will end, just as analogies break down, so the film will end and you, the viewer, will be left sat in the darkened room. Only now, you will have certain analogies in view, that hitherto might have lay in your unconscious. 